\title{
Continued tobacco consumption during pregnancy and women's depression and anxiety symptoms
}

\author{
M. Carmen Míguez ${ }^{1} \cdot$ Beatriz Pereira ${ }^{1} \cdot$ Tiago Miguel Pinto $^{2} \cdot$ Bárbara Figueiredo $^{2}$
}

Received: 7 June 2019/Revised: 31 July 2019/Accepted: 5 October 2019

(C) Swiss School of Public Health (SSPH+) 2019

\begin{abstract}
Objectives This study aimed to analyse depression and anxiety symptoms changes from the first to the third trimester of pregnancy in non-smokers versus quitters versus continuous smokers, and the contribution of depression and anxiety symptoms to continued tobacco consumption during pregnancy.

Methods The sample comprises 850 Spanish pregnant women (595 non-smokers, 123 quitters, and 132 continuous smokers), assessed at the first and the third trimester of pregnancy with a questionnaire concerning socio-demographic, obstetric, and tobacco consumption information, and measures of depression and anxiety.

Results Continuous smokers during pregnancy showed more depression and anxiety symptoms than both non-smokers and quitters and no changes from the first trimester to the third trimester of pregnancy, while both non-smokers and quitters revealed a decrease in depression and anxiety symptoms. More anxiety symptoms at the first trimester (OR 1.03) and depression symptoms at the third trimester (OR 1.14) were associated with continued smoking during pregnancy.

Conclusions Anxiety and depression symptoms need to be considered to screening for women at risk of smoking during pregnancy. Future prenatal smoking cessation interventions must take into account these variables.
\end{abstract}

Keywords Pregnancy $\cdot$ Tobacco consumption · Continuous smokers $\cdot$ Depression · Anxiety

\section{Introduction}

Tobacco consumption during pregnancy is one of the main factors associated with adverse health outcomes for women and their children (USDHHS 2014). Although some women spontaneously quit smoking after knowing that they are pregnant (Schneider et al. 2010), other pregnant women continue smoking even knowing the risk involved.

Previous studies on tobacco consumption during pregnancy have compared smokers with quitters characteristics (e.g. Coleman-Cowger et al. 2013; Erlingdottir et al. 2014; Goedhart et al. 2009) or smokers with non-smokers (Al-

M. Carmen Míguez

mcarmen.miguez@usc.es

1 Department of Clinical Psychology and Psychobiology, Faculty of Psychology, University of Santiago de Compostela, Campus Vida, 15782 Santiago de Compostela, Spain

2 School of Psychology, University of Minho, Campus de Gualtar, Braga, Portugal
Sahab et al. 2010; Giglia et al. 2007; Orr et al. 2012). Including women who have never smoked and those who quit smoking during pregnancy in the same non-smokers group (e.g. Al-Sahab et al. 2010; Orr et al. 2012) may provide underrepresented data as different consumption profiles and associated factors are considered as the same one. However, knowing about the differences between smokers and quitters may provide relevant information, namely regarding why some smokers quit and others continue smoking during pregnancy. On the other hand, exploring the differences among the three groups-nonsmokers, quitters, and continuous smokers across pregnancy - may also add relevant information to the field of tobacco consumption, mainly regarding the benefits of quitting smoking during pregnancy.

More information on the main aspects associated with continuing smoking throughout pregnancy is needed to target relevant causes and to offer the necessary specific support to quit smoking during pregnancy. Research on this subject lacks a longitudinal and prospective approach with biochemical test of smoking abstinence, as data may be 
biased by women's memory and/or by social desirability due to social pressure on quitting smoking (Míguez and Pereira 2018). Studies have been based mostly on nonconfirmed information of abstinence from retrospective self-reports (e.g. Dupraz et al. 2013) or cross-sectional surveys focusing on abstinence in one specific moment of pregnancy (Erlingdottir et al. 2014; Giglia et al. 2007; Goedhart et al. 2009). Cross-sectional studies show partial results because they do not assess changes in major variables that could differently affect consumption depending on the period of gestation evaluated. Therefore, it is necessary to use a robust methodology that allows the obtention of more precise data.

Smoking during pregnancy has been associated with several socio-demographic risk factors, such as a young age and low educational level (Balwicki et al. 2016; Krstev et al. 2012; Orton et al. 2014), low economic level (Balwicki et al. 2016; Krstev et al. 2012; Maxson et al. 2012), unemployment (Balwicki et al. 2016; Orton et al. 2014; Smedberg et al. 2014), unexpected pregnancy (Suzuki et al. 2010), and having a smoking partner (Orr et al. 2012). On the other hand, women intending to breastfeed were found to be less likely to smoke during pregnancy (Haslam et al. 2003). Smoking during pregnancy has also been associated with depression and/or anxiety symptoms, but results are somewhat controversial. The majority (Linares-Scott et al. 2009; Maxson et al. 2012; Smedberg et al. 2014; Tong et al. 2016), but not all (Beijers et al. 2014; Blaga et al. 2017; Meghea et al. 2010), studies have linked smoking with the presence of depression or depression symptoms. Moreover, although the relationship between anxiety and smoking in pregnancy has been less investigated, some studies suggest that smoking during pregnancy is more prevalent in women with higher levels of anxiety (Blaga et al. 2017; Goedhart et al. 2009; Tong et al. 2016), while others have not found this association (e.g. Beijers et al. 2014; Massey and Compton 2013).

Pregnancy is a stage of critical psychological vulnerability for women. Tobacco consumption and psychological adjustment problems during pregnancy are strongly associated and have a similar adverse impact on the infant health and development. For example, maternal depression during pregnancy was found to increase the risk of prematurity, low birthweight, and later emotional and behavioural problems (see Field 2011). Depression and anxiety symptoms were associated with tobacco consumption, and tobacco consumption was found to affect depression and anxiety symptoms (Taylor et al. 2014). However, the interaction between these two aspects need to be better explored, mainly at different times of pregnancy, because it is unclear whether these depressive and anxious symptoms are influenced by tobacco consumption depending on the trimester of pregnancy. Many smokers think that smoking offers mental health benefits; however, some studies show the opposite, that is, an association between smoking cessation and a decrease in depression, anxiety, and stress, as well as an improvement in mood and quality of life (Taylor et al. 2014). To explore the influence of continuing or quitting smoking during pregnancy on women's depression and anxiety symptoms over pregnancy is relevant for clinical practice and research.

This study aimed to analyse: (1) anxiety and depression symptoms changes from the first to the third trimester of pregnancy in non-smokers versus quitters versus continuous smokers and (2) the contribution of anxiety and depression symptoms to continued tobacco consumption in women from the first to the third trimester of pregnancy.

\section{Methods}

\section{Participants}

A total of 915 pregnant women were invited to participate in the study, 11 declined to participate and three could not be enrolled, as they were not proficient in Spanish. From the 901 women who accepted to participate and were assessed at the first trimester, 28 had suffered a miscarriage, 14 could not be contacted, and two declined to participate at the third trimester of pregnancy. From 857 (95.1\%) women assessed at the third trimester of pregnancy, seven reported having quit smoking after the first trimester of pregnancy and were excluded from the analyses. Therefore, the sample of this study was comprised of 850 pregnant women assessed at the first ( $M=9.93$ gestational weeks; $S D=4.19$; age range 4-20 weeks) and third ( $M=33.28$ gestational weeks; $S D=2.04$; age range 26-40) trimester of pregnancy. Participants' age ranged between 18 and 46 years old $(M=32.72$ years; $S D=$ 4.35). Most participants were married or cohabiting $(83.3 \%)$. More than half were over 30 years old $(72.0 \%)$, were employed at the first trimester of pregnancy $(71.2 \%)$, were primiparous $(66.4 \%)$, had university studies $(53.1 \%)$, and had a maximum household income of 2000 euros net per month (57.4\%).

More than half of pregnant women had never smoked or had given up smoking before pregnancy $(70.0 \% ; n=595)$, while $14.5 \%(n=123)$ spontaneously quitted at the first pregnancy trimester and $15.5 \% \quad(n=132)$ continued smoking during pregnancy.

\section{Procedure}

The present research was conducted in accordance with the Declaration of Helsinki and received previous approval from the ethical commission of all institutions involved. 
Pregnant women attending a primary health public care service in Northwest Spain (December 2012-September 2014) were recruited through consecutive probabilistic sampling at the first trimester of pregnancy. The number of births in the year preceding the study according to official data was used to calculate the sample size and to insure representativeness with a confidence level of $95 \%$ and an accuracy of $3.4 \%$. The aims and procedures were explained, and pregnant women who were willing to participate provided a written informed consent. Following, two trained psychologists carried out the interviews individually.

This is a observational prospective longitudinal study with two assessment waves, at the first and the third trimester of pregnancy. Women were assessed at both assessment waves with an ad hoc questionnaire on sociodemographic, obstetric, and tobacco consumption information, and measures of depression and anxiety symptoms. The average time for assessment of each participant in each trimester was $20 \mathrm{~min}$. At the third trimester, an appointment was performed by telephone to schedule the interview. Pregnant women choose the day, time, and place of the interview. Most women $(80.0 \%)$ preferred to perform this assessment in their homes.

To avoid potential biases in the classification of women in their consumption group, biochemical tests (cotinine concentration in urine at the first trimester of pregnancy and carbon monoxide in expired air at the third trimester of pregnancy) were performed to confirm the self-reported consumption status. Likewise, in regression analysis, the socio-demographic and obstetric variables that differentiated the consumption groups (confounding variables) were controlled.

Pregnant women were classified into three groups based on their self-report tobacco consumption and the results of the biochemical test: (1) non-smokers-non-smoking before (or since long time before) pregnancy and throughout pregnancy; (2) quitters-quitting smoking at the first trimester of pregnancy (when pregnancy suspected/confirmed) and non-smoking throughout pregnancy; (3) continuous smokers-maintained tobacco consumption throughout pregnancy.

\section{Measures}

\section{Socio-demographic and tobacco consumption information}

Information regarding socio-demographic characteristics (e.g. age, marital and occupational status, parity, education, and monthly household income), psychopathology diagnosed, pregnancy-related variables (e.g. number of gestational weeks, planned pregnancy, and breastfeeding intention) and consumption information (e.g. smoking status and having a partner who smokes) was obtained for this study.

Self-reports of smoking abstinence were biochemically verified through urinary cotinine by Cotinine Test Medimarketing (cut-off $200 \mathrm{ng} / \mathrm{mL}$ ) at the first trimester and through the evaluation of expired air carbon monoxide (CO) at the third trimester (cut-off of 5 ppm) using a carbon monoxide monitor (Model Smokerlyzer Pico Simple; Bedfont Technical Instruments Ltd., Sittingbourne, Kent, UK). Biochemical measurement and self-report were combined to establish smoking status.

\section{Edinburgh Postnatal Depression Scale (EPDS; Cox et al. 1987)}

EPDS is a 10-item self-reported questionnaire designed to assess the intensity of depression symptoms within the previous 7 days. Higher scores indicate more intensity of depression symptoms. It is the most widely used questionnaire for detection of postpartum depressive symptoms, although it has also been validated to detect depression during pregnancy. In the Spanish validation (Vázquez and Míguez 2019), the recommended cut-off score is 10 . In the present study, the EPDS showed good internal consistency (Cronbach's $\alpha=0.85$ at the first trimester of pregnancy and 0.77 at the third trimester of pregnancy).

\section{State Anxiety Scale of State-Trait Anxiety Inventory (STAI;} Spielberger et al. 1970; Spanish version TEA, 1982)

The STAI-S consists of 20-item self-reported scale designed to assess the current state of anxiety. Higher scores indicate higher anxiety symptoms. The STAI-S Spanish version proposed a clinical cut-off of 32 (75th percentile) to screen for high anxiety in women. In the present study, the STAI-S showed excellent internal consistency (Cronbach's $\alpha=0.94$ at the first trimester of pregnancy and 0.91 at the third trimester).

\section{Data analysis}

Preliminary analyses were performed using Chi-square tests to analyse the characteristics (socio-demographic, obstetric, and psychological) of smoking status groups (non-smokers, quitters, continuous smokers). A repeatedmeasures multivariate analysis of variance (MANOVA) was performed to analyse anxiety and depression symptoms changes from the first to the third trimester of pregnancy in non-smokers versus quitters versus continuous smokers. The model included smoking status groups as the between-subjects factor and women's depression and anxiety symptoms as within-subjects' factors with two levels: EPDS and STAI-S scores at the first and the third 
trimester of pregnancy. A MANOVA was performed to explore differences between the smoking status groups on women's depression and anxiety symptoms at the first and the third trimester of pregnancy. The model included smoking status groups as the independent variable and women's depression and anxiety symptoms (at the first and the third trimester of pregnancy) as dependent variables. Pairwise comparisons were applied to assess within and between group differences.

A three-step logistic regression was performed to analyse anxiety and depression symptoms associated with continued tobacco consumption in women from the first to the third trimester of pregnancy. The first step (enter method) was performed to control confounding variables associated with the smoking status groups (specifically, marital status, education, monthly household income, parity, smoking partner, pregnancy influenced work, planned pregnancy, breastfeeding intention, and previous psychopathology diagnosed). The second and third steps were made to know which psychological variables predicted consumption status, specifically anxiety and depression symptoms at the first and third trimester of pregnancy. The second step (stepwise method) was performed to clarify whether the strongest predictor of continued tobacco consumption in women during pregnancy is anxiety or depression symptoms at the first trimester of pregnancy. The third step (stepwise method) was performed to clarify whether there are anxiety or depression symptoms at the third trimester of pregnancy that are associated with continued tobacco consumption in women during pregnancy (adjusting the model for anxiety and depression symptoms at the first trimester of pregnancy). All the three steps included continued tobacco consumption during pregnancy as dependent variable.

Cramer's V coefficients and partial eta-squared $\left(\eta p^{2}\right)$ were calculated to estimate the effect size. Data were analysed with IBM SPSS 23.0 version (SPSS Inc, Chicago).

\section{Results}

\section{Preliminary analyses: associations between smoking status and socio-demographic, obstetric, and psychological variables}

Significant associations were found between smoking status and socio-demographic, obstetric, and psychological characteristics (see Table 1). Regarding socio-demographic characteristics, non-smokers are more likely to be married or living with partner than continuous smokers during pregnancy, to be higher educated, less likely to receive a monthly salary lower than $2000 €$, more likely to live with a non-smoking partner than quitters or continuous smokers, and less likely to be multiparous than quitters. Quitters are more likely to be higher educated and less likely to live with a non-smoking partner than continuous smokers during pregnancy. Regarding obstetric characteristics, non-smokers are more likely to report that pregnancy did not influence their work than quitters or continuous smokers during pregnancy, and more likely to report that pregnancy was desired and that they intended to breastfeed their infant than continuous smokers. Regarding psychological characteristics, non-smokers are less likely to present previous psychopathology than continuous smokers, less likely to be depressed or anxious at the first trimester of pregnancy than quitters or continuous smokers, and less likely to be depressed or anxious at the third trimester of pregnancy than continuous smokers during pregnancy.

\section{Differences on women's depression and anxiety from the first to the third trimester of pregnancy, according to smoking status}

The repeated-measures MANOVA revealed significant multivariate (Wilk's Lambda $=0.98, \quad F_{2,846}=6.87$, $\left.p=0.001, \eta p^{2}=0.02\right)$ and univariate time effects on women's depression and anxiety symptoms. Women's depression and anxiety symptoms decreased from the first to the third trimester of pregnancy. No significant effects of the interaction between time and smoking status were found on women's depression and anxiety. However, pairwise comparisons noted that non-smokers and quitters revealed a significant decrease on depression and anxiety symptoms, while continuous smokers during pregnancy revealed no significant changes on depression and anxiety symptoms from the first to the third trimester of pregnancy (see Table 2 and Fig. 1A, B).

The MANOVA results were statistically significant. The univariate results revealed significant effects of smoking status on women's depression $\left(F_{2,847}=14.98, p<0.001\right.$, $\left.\eta p^{2}=0.03\right)$ and anxiety symptoms $\left(F_{2,847}=14.49\right.$, $\left.p<0.001, \eta p^{2}=0.03\right)$ at the first trimester of pregnancy and on women's depression $\left(F_{2,847}=16.88, p<0.001\right.$, $\left.\eta p^{2}=0.04\right)$ and anxiety symptoms $\left(F_{2,847}=14.56\right.$, $\left.p<0.001, \eta p^{2}=0.03\right)$ at the third trimester of pregnancy. Pairwise comparisons revealed that continuous smokers during pregnancy showed more depression and anxiety symptoms at the first and at the third trimester of pregnancy than non-smokers and quitters. No differences were found between non-smokers and quitters on depression and anxiety symptoms at the first and the third trimester of pregnancy. 
Table 1 Associations between continued smoking status and socio-demographic, obstetric, and psychological variables among Spanish pregnant women in 2014

$\begin{array}{llllll}(1) & (2) & (3) & \chi^{2} & V & \text { Group comparisons } \\ \text { Non-smokers } & \text { Quitters } & \text { Smokers } & & \\ (n=595) & (n=123) & (\mathrm{n}=132) & & \\ \%(n) & \%(n) & \%(n) & & \\ \end{array}$

Socio-demographic variables

Age (years)

$$
>30
$$$$
\leq 30
$$

Marital status

Married/cohabiting

Single/divorced

Higher education

Yes

No

Occupational status

$$
\begin{aligned}
& \text { Employed } \\
& \text { Unemployed }
\end{aligned}
$$

Monthly salary

$$
\begin{aligned}
& >2000 \\
& \leq 2000
\end{aligned}
$$

Parity

Primiparous

Multiparous

Smoking partner

Yes

No

Obstetric variables

Pregnancy-influenced work

Yes
No

Pregnancy desired

Yes

No

Breastfeeding intention

$$
\text { Yes }
$$

No

Psychological variables

Psychopathology

Yes

No

Depression at first trimester of pregnancy

EPDS $\geq 10$

EPDS $<10$

Anxiety at first trimester of pregnancy
STAI-S $\geq 32$
STAI-S $<32$

$$
73.3 \text { (436) }
$$

26.7 (159)

85.5 (509)

14.5 (86)

$60.5(360)$

39.5 (235)

72.9 (434)

27.1 (161)

40.1 (222)

59.9 (332)

63.0 (375)

37.0 (220)

21.3 (127)

78.7 (468)

10.4 (62)

89.6 (533)

89.7 (534)

10.3 (61)

89.4 (532)

10.6 (63)

11.4 (68)

88.6 (527)

13.8 (17)

86.2 (106)

20.5 (27)

79.5 (105)

12.4 (74)

87.6 (521)

22.8 (28)

77.2 (95)

30.3 (40)

69.7 (92)

$5.2(31)$

94.8 (564)
9.8 (12)

90.2 (111)
16.7 (22)

83.3 (110)
18.9 (25)
1.60

$1=2=3$

$1=2=3$

$9.05 * *$

0.10

$1=2 ; 1>3 * ; 2=3$

$1=2=3$

$58.53^{* * * *}$

0.26

$1>2>3^{* * * *}$

$1<2<3 * * *$

4.57

$1=2=3$

$1=2=3$

$11.25 * *$

$0.121=2=3$

$1<2,3 *$

$13.12 * *$

0.12

$1<2 * * ; 1,2=3$

$1=2=3$

$114.18^{* * *}$

0.37

$1<2<3^{* * * *}$

$1>2>3 * * *$

$9.44 * *$

0.11

$1=2=3$

$1>2,3^{*}$

$7.71 *$

0.10

$1=2 ; 1>3 * ; 2=3$

$1=2=3$

$7.10 *$

0.09

$1=2 ; 1>3^{*} ; 2=3$

$1=2=3$

$7.75^{*}$

0.10

$1=2 ; 1<3^{*} ; 2=3$

$1=2 ; 1>3 * ; 2=3$

$28.58 * * *$

0.18

$1<2,3^{* * *}$

$1>2,3^{* * *}$

$20.98 * * *$

0.16

$1<2,3 * * *$

$1>2,3 * * *$ 
Table 1 (continued)

$\begin{array}{llllll}(1) & (2) & (3) & \chi^{2} & V & \text { Group comparisons } \\ \text { Non-smokers } & \text { Quitters } & \text { Smokers } & & \\ (n=595) & (n=123) & (\mathrm{n}=132) & & \\ \%(n) & \%(n) & \%(n) & & \\ \end{array}$

Depression at third trimester

of pregnancy

\begin{tabular}{|c|c|c|c|c|c|c|}
\hline $\mathrm{EPDS} \geq 10$ & $8.9(53)$ & $12.2(15)$ & $16.7(22)$ & $7.26 *$ & 0.09 & $1=2 ; 1<3^{*} ; 2=3$ \\
\hline EPDS $<10$ & $91.1(542)$ & $87.8(108)$ & $83.3(110)$ & & & $1=2 ; 1>3^{*} ; 2=3$ \\
\hline \multicolumn{7}{|c|}{$\begin{array}{l}\text { Anxiety at third trimester } \\
\text { of pregnancy }\end{array}$} \\
\hline STAI-S $\geq 32$ & $3.7(22)$ & $7.3(9)$ & $9.1(12)$ & $8.07 *$ & 0.10 & $1=2 ; 1<3^{*} ; 2=3$ \\
\hline STAI-S $<32$ & $96.3(573)$ & 92.7 (114) & $90.9(120)$ & & & $1=2 ; 1>3^{*} ; 2=3$ \\
\hline
\end{tabular}

Data collection: Spain, 2013-2014

$V$ Cramer's V, EPDS Edinburgh Postnatal Depression Scale, STAI-S State Anxiety Scale of State-Trait Anxiety Inventory

$* p<0.05 ; * * p<0.01 ; * * * p<0.001$

Table 2 Between and within differences on Spanish women's depression and anxiety symptoms from the first to the third trimester of pregnancy, according to continued smoking status in 2014

\begin{tabular}{|c|c|c|c|c|c|c|c|c|c|}
\hline \multirow[t]{2}{*}{ Symptoms } & \multicolumn{2}{|c|}{$\begin{array}{l}(1) \\
\text { Non-smokers } \\
(n=595)\end{array}$} & \multicolumn{2}{|c|}{$\begin{array}{l}(2) \\
\text { Quitters } \\
(n=123)\end{array}$} & \multicolumn{2}{|c|}{$\begin{array}{l}(3) \\
\text { Smokers } \\
(n=132)\end{array}$} & \multirow[t]{2}{*}{$F$} & \multirow[t]{2}{*}{$d f$} & \\
\hline & $M$ & $S D$ & $M$ & $S D$ & $M$ & $S D$ & & & \\
\hline \multicolumn{10}{|l|}{ Depression } \\
\hline First trimester (a) & 4.72 & 4.11 & 5.60 & 4.82 & 6.99 & 5.22 & $14.98 * * *$ & 2,847 & $1,2<3^{I}$ \\
\hline \multirow[t]{2}{*}{ Third trimester (b) } & 4.21 & 3.52 & 4.59 & 3.87 & 6.20 & 3.48 & $16.88 * * *$ & 2,847 & $1,2<3^{\text {II }}$ \\
\hline & \multicolumn{2}{|c|}{$a>b^{1}$} & \multicolumn{2}{|l|}{$a>b^{2}$} & \multicolumn{2}{|l|}{$a=b^{3}$} & & & \\
\hline \multicolumn{10}{|l|}{ Anxiety } \\
\hline First trimester (a) & 14.00 & 9.45 & 15.90 & 11.30 & 19.27 & 12.81 & $14.49 * * *$ & 2,847 & $1,2<3^{\text {III }}$ \\
\hline \multirow[t]{2}{*}{ Third trimester (b) } & 12.57 & 8.54 & 13.54 & 8.73 & 17.16 & 10.15 & $14.56 * * *$ & 2,847 & $1,2<3^{\text {IV }}$ \\
\hline & \multicolumn{2}{|l|}{$a>b^{1}$} & \multicolumn{2}{|c|}{$a>b^{2}$} & \multicolumn{2}{|l|}{$a=b^{3}$} & & & \\
\hline
\end{tabular}

Data collection: Spain, 2013-2014

$M$ Mean, SD Standard Deviation, multivariate effects of repeated-measures MANOVA, Wilk's Lambda $=0.98, \quad F_{2,846}=6.87, \quad p=0.001, \eta p^{2}=0.02 ;$ multivariate effects of MANOVA, Wilk's Lambda $=0.93, F_{8,1688}=7.97, p<0.001, \eta p^{2}=0.04$

${ }^{1}$ Pairwise comparisons applied to non-smokers group: depression symptoms, $p=0.015$, anxiety symptoms, $p=0.003$

${ }^{2}$ Pairwise comparisons applied to quitters group: depression symptoms, $p=0.035$, anxiety symptoms, $p=0.045$

${ }^{3}$ Pairwise comparisons applied to smokers group: depression symptoms, $p=0.117$, anxiety symptoms, $p=0.127$

${ }^{\mathrm{I}} 1$ versus $2, p=0.130 ; 1$ versus $3, p<0.001 ; 2$ versus $3, p=0.036$

${ }^{\text {II }} 1$ versus $2, p=0.814 ; 1$ versus $3, p<0.001 ; 2$ versus $3, p=0.001$

${ }^{\text {III }} 1$ versus $2, p=0.190 ; 1$ versus $3, p<0.001 ; 2$ versus $3, p=0.028$

${ }^{\mathrm{IV}} 1$ versus $2, p=0.816 ; 1$ versus $3, p<0.001 ; 2$ versus $3, p=0.003$

$* * * p<0.001$

\section{Depression and anxiety symptoms associated with continued tobacco consumption in women from the first to the third trimester of pregnancy}

The first step regression was statistically significant $\left(\chi_{7}^{2}=23.32, p=0.006\right)$. The model explained $10-14 \%$ of the variance in continued tobacco consumption (Cox and Snell $R^{2}=0.10$, Nagelkerke $R^{2}=0.14$ ) and correctly classified $66.4 \%$ of cases. Women without a college degree $(\mathrm{OR}=2.46)$ and with smoker partner $(\mathrm{OR}=2.27)$ were more likely to continue smoking during pregnancy. 


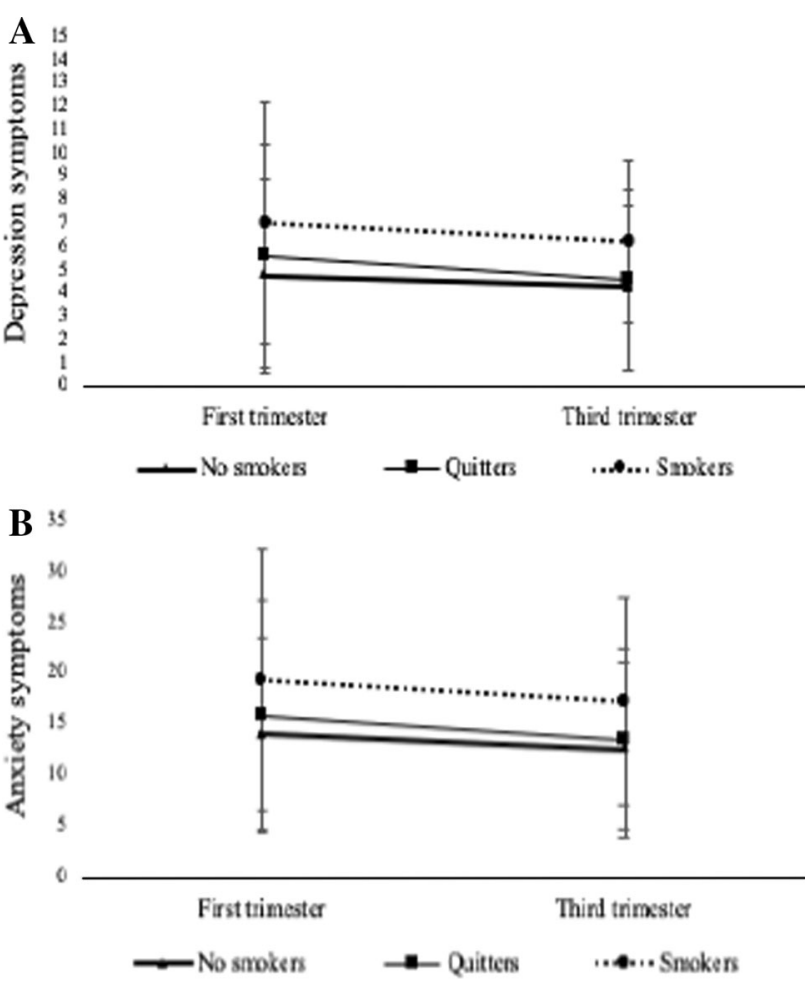

Fig. 1 Differences on Spanish women's depression (Edinburgh Postnatal Depression Scale mean scores) and anxiety symptoms (State Anxiety Scale of State-Trait Anxiety Inventory mean scores) from the first to the third trimester of pregnancy, according to smoking status in 2014. Significant changes are represented with a continuous line

The second step regression was statistically significant $\left(\chi_{10}^{2}=29.63, p=0.001\right)$. The model explained $13-17 \%$ of the variance in continued tobacco consumption (Cox and Snell $R^{2}=0.13$, Nagelkerke $R^{2}=0.17$ ) and correctly classified $67.3 \%$ of cases. More anxiety symptoms at the first trimester $(\mathrm{OR}=1.03)$ increased the probability of continued smoking during pregnancy.

The third step regression was statistically significant $\left(\chi_{10}^{2}=38.64, p=0.001\right)$. The model explained $17-22 \%$ of the variance in continued tobacco consumption (Cox and Snell $R^{2}=0.17$, Nagelkerke $R^{2}=0.22$ ) and correctly classified $67.3 \%$ of cases. More depression symptoms at the third trimester $(\mathrm{OR}=1.14)$ were associated with continued smoking during pregnancy (see Table 3 ).

\section{Discussion}

Depression and anxiety symptoms trajectories from the first to the third trimester of pregnancy were in the present study similar to the ones found in the literature, that is a decrease in anxiety and depression symptoms from the first to the third trimester of pregnancy (e.g. Andersson et al. 2006; Figueiredo and Conde 2011). Interestingly, depression and anxiety symptoms changes from the first to the third trimester of pregnancy are different in non-smokers versus quitters versus continuous smokers during pregnancy, with continuous smokers not exhibiting the normative decrease in depression and anxiety symptoms across pregnancy, as found in quitters and non-smokers. Moreover, anxiety symptoms at the first trimester were associated with continued smoking during pregnancy. Additionally, continued smoking during pregnancy was associated with more depression symptoms at the third trimester. These results clarify how anxiety and depression symptoms are related to continued smoking during pregnancy.

Several socio-demographic, obstetric, and psychological differences were found between continuous smokers, quitters, and non-smokers. These data suggest that two-bytwo smoking status group comparisons (e.g. smokers vs. non-smokers) performed in previous studies (e.g. Al-Sahab et al. 2010; Orr et al. 2012) may underrepresent the results. The group of women who did not smoke, formed by nonsmokers and quitters, is not an uniform group, and the variables associated with not smoking during pregnancy are not always the same as those associated with the cessation of consumption. For example, regarding parity, the group of non-smokers has the highest percentage of multiparous women $(37.0 \%)$, while the group of quitters has the highest percentage of primiparous women $(79.7 \%)$. Therefore, joining both groups could result that the differences in function of parity were minimized or even disappeared.

Regression analyses showed that to have a low level of studies, to have a smoking partner, and to present higher levels of anxiety symptoms at the first trimester of pregnancy and higher levels of depression symptoms at the third trimester are associated with continuous consumption during pregnancy. When only the first trimester was considered, results showed that higher levels of anxiety symptoms increased the probability of continued smoking during pregnancy. The greater importance of anxiety symptoms at the first trimester of pregnancy may be related to the fact that the early pregnancy period represents a time of great risks for pregnancy (Mook-Kanamori et al. 2010). Pregnant women not only have to adapt to their new situation, but also have to face concerns about the viability of pregnancy and/or the health of the foetus. The relationship between lower education and continuous tobacco consumption could be explained by not being fully aware of the harmful effects of tobacco use on the health of both the pregnant women and the unborn child (Driezen et al. 2016). In addition, living with other smokers is also associated with increased need to smoke due to a "contagion effect" and mean a greater availability of tobacco at home that is difficult for the women's control of stimulus (Doz et al. 2004). The relationship between higher levels of 
Table 3 Depression and anxiety symptoms as predictors of continued tobacco consumption (quitters vs. continuous smokers) among Spanish pregnant women

\begin{tabular}{|c|c|c|c|c|c|}
\hline & $\beta$ & Wald & $p$ & OR & $95 \% \mathrm{CI}$ \\
\hline \multicolumn{6}{|l|}{ Step 1 (enter method) } \\
\hline Marital status & 0.05 & 0.02 & 0.90 & 1.05 & $0.51-2.16$ \\
\hline No college degree & 0.90 & 6.50 & $0.01 *$ & 2.46 & $1.23-4.95$ \\
\hline Parity & 0.66 & 3.73 & 0.05 & 1.93 & $0.99-3.76$ \\
\hline Pregnancy-influenced work & 0.07 & 0.03 & 0.86 & 0.94 & $0.47-1.88$ \\
\hline Pregnancy desired & 0.07 & 0.03 & 0.86 & 0.93 & $0.42-2.07$ \\
\hline Breastfeeding intention & 0.16 & 0.14 & 0.71 & 1.17 & $0.52-2.64$ \\
\hline Previous psychopathology & 0.55 & 1.93 & 0.17 & 0.58 & $0.27-1.25$ \\
\hline Salary & 0.54 & 1.99 & 0.16 & 1.72 & $0.81-3.64$ \\
\hline Smoking partner & 0.82 & 7.30 & $0.01 *$ & 2.27 & $1.25-4.10$ \\
\hline \multicolumn{6}{|l|}{ Step 2 (stepwise method) } \\
\hline Marital status & 0.19 & 0.25 & 0.62 & 1.21 & $0.57-2.55$ \\
\hline No college degree & 0.86 & 5.76 & $0.02 *$ & 2.37 & $1.17-4.78$ \\
\hline Parity & 0.58 & 2.71 & 0.10 & 1.78 & $0.90-3.53$ \\
\hline Pregnancy-influenced work & 0.10 & 0.07 & 0.79 & 1.10 & $0.54-2.26$ \\
\hline Pregnancy desired & 0.18 & 0.18 & 0.68 & 0.84 & $0.37-1.91$ \\
\hline Breastfeeding intention & 0.09 & 0.05 & 0.83 & 1.10 & $0.48-2.52$ \\
\hline Previous psychopathology & 0.48 & 1.41 & 0.24 & 0.62 & $0.28-1.37$ \\
\hline Salary & 0.54 & 1.88 & 0.17 & 1.71 & $0.80-3.67$ \\
\hline Smoking partner & 0.92 & 8.74 & $<0.01 * *$ & 2.51 & $1.36-4.63$ \\
\hline Anxiety symptoms at first trimester & 0.03 & 6.02 & $0.01^{*}$ & 1.03 & $1.01-1.06$ \\
\hline \multicolumn{6}{|l|}{ Step 3 (stepwise method) } \\
\hline Marital status & 0.21 & 0.30 & 0.58 & 1.24 & $0.58-2.64$ \\
\hline No college degree & 0.83 & 5.04 & $0.03 *$ & 2.29 & $1.11-4.72$ \\
\hline Parity & 0.57 & 2.52 & 0.11 & 1.77 & $0.87-3.59$ \\
\hline Pregnancy-influenced work & 0.06 & 0.03 & 0.87 & 1.06 & $0.52-2.19$ \\
\hline Pregnancy desired & 0.17 & 0.15 & 0.70 & 0.85 & $0.37-1.93$ \\
\hline Breastfeeding intention & 0.17 & 0.15 & 0.70 & 1.18 & $0.50-2.77$ \\
\hline Previous psychopathology & 0.37 & 0.83 & 0.36 & 0.69 & $0.31-1.54$ \\
\hline Salary & 0.50 & 1.50 & 0.22 & 1.64 & $0.74-3.64$ \\
\hline Smoking partner & 0.91 & 8.09 & $<0.01 * *$ & 2.48 & $1.33-4.63$ \\
\hline Anxiety symptoms at first trimester & 0.03 & 5.42 & $0.02 *$ & 1.03 & $1.01-1.06$ \\
\hline Depression symptoms at third trimester & 0.14 & 8.42 & $<0.01 * *$ & 1.14 & $1.05-1.25$ \\
\hline
\end{tabular}

Data collection: Spain, 2013-2014

$O R$ odds ratio, $C I$ confidence interval

$* p<0.05 ; * * p<0.01$ anxiety symptoms at the first trimester and continuing smoking have been found in the literature (e.g. Goedhart et al. 2009) and could be explained by the presence of more stress according to the identified risk factors present in women who continued smoked during pregnancy (they were less likely to be married or partnered and to receive a higher monthly salary). Moreover, this relationship can also be sustained by the belief that smoking helps to relax and control negative emotions (Irwin et al. 2005), becoming a coping strategy. However, our data do not support this belief, since no decrease in the levels of anxiety and depression across pregnancy was found in women who continued smoking during pregnancy, contrarily to what was observed in both non-smokers and quitters. Moreover, when both the first and the third trimesters were considered, a significant association was found between continuous tobacco consumption and depression symptoms at the third trimester. Although smoking can be used as a tool to cope with negative mood (Zhu and Valvo 2002), our results suggested that continued smoking during pregnancy could increase depression symptoms.

Regarding the differences on women's depression and anxiety symptoms from the first to the third trimester of pregnancy according to smoking status, our data show that 
quitting is associated with a reduction in depression and anxiety symptoms, so there is an improvement in mental health, as noted by Taylor et al. (2014). Thus, it can be observed that the levels of depression and anxiety symptoms of women who spontaneously quit smoking at the first trimester of pregnancy decrease to similar levels of women who do not smoke, as non-significant differences were found between both groups. Likewise, our data also seem to corroborate that smoking could increase mental health problems (Flensborg-Madsen et al. 2011; Minichino et al. 2013). Continuous smokers maintain the highest levels of anxiety and depression symptoms throughout pregnancy, as significant differences were found with the group of non-smokers and quitters both at the first and at the third trimester of pregnancy.

One variable that stands out and which contribute should be better analysed in future studies on smoking during pregnancy and the post-partum period is breastfeeding intention and duration. In line with the literature, significant differences between the smoking status groups were found regarding breastfeeding intention, with smokers having the lower intentionality to breastfeed. Previous studies have related both depression symptoms and tobacco consumption status to breastfeeding. Specifically, higher levels of depression symptoms both during pregnancy (Figueiredo et al. 2014; Ystrom 2012) and during the postpartum (Ystrom 2012) were associated with breastfeeding no-intention, no-initiation, or early cessation. Likewise, continued smoking during pregnancy was related to breastfeeding no-initiation or a shorter duration (Giglia et al. 2007; Suzuki et al. 2010). A relationship between quitting smoking in early pregnancy and the intention to breastfeed was found in the present study and has also been suggested in the literature. Women who intend to breastfeed are less likely to smoke and more likely to spontaneously quit smoking during pregnancy (Haslam et al. 2003; Joseph et al. 2017). These data suggest the importance of promoting breastfeeding to improve smoking cessation and reduce depression symptoms, as well as the possible importance of improving smoking cessation and reducing depression symptoms to promote breastfeeding.

Some limitations should be considered. Pre-pregnancy psychological assessments were not conducted, which does not allow to know how pregnancy affected the process of tobacco quitting due to anxiety and depression symptoms. In addition, depression and anxiety symptoms were assessed through self-reported measures.

Despite these limitations, this study has several strengths. Firstly, a large sample was used to study simultaneously relevant factors that previous research has found to be related to smoking during pregnancy. Secondly, this is a longitudinal study that assessed continued consumption and continued abstinence over pregnancy and performed comparisons between the three consumption groups (non-smokers, quitters, and continuous smokers). We consider that the variables associated with continuous abstinence or consumption are the most important variables to analyse because the objective should not be to achieve abstinence at a certain time of pregnancy, but the maintenance during all pregnancy. Moreover, the pregnant women's self-reports of smoking abstinence were biochemically validated to control for social desirability bias. This is particularly relevant during pregnancy when higher social pressure for women not smoking is present (Míguez and Pereira 2018).

In conclusion, this study showed how levels of depression and anxiety are influenced both by the time of pregnancy evaluated and by the smoking status, with continuous smokers during pregnancy at risk of increasing anxiety and depression symptoms. The main clinical implications of our results concern the relevance of screening for anxiety and depression early in pregnancy to identify women at risk of smoking during the entire pregnancy. Also, this study reinforces the idea that future prenatal smoking cessation interventions must take into account these variables.

Acknowledgements We would like to express our gratitude to the midwives at the surveyed Primary Health Care Centers for their valuable assistance. We sincerely appreciate the support by research contract inherent to a predoctoral research training funded by Axudas de Apoio a Etapa Predoctoral do Plan Galego 2011/2015 (Plan 12C) to the second author (Beatriz Pereira). Lastly, we would like to show our gratitude especially to the pregnant women for their patience and generous collaboration in this study.

Funding No external funding involved.

\section{Compliance with ethical standards}

Conflict of interest The authors declare that they have no conflict of interest

Ethical approval All procedures performed in studies involving human participants were in accordance with the ethical standards of the institutional and/or national research committee and with the 1964 Declaration of Helsinki and its later amendments or comparable ethical standards.

Informed consent Informed consent was obtained from all individual participants included in the study.

\section{References}

Al-Sahab B, Saqib M, Houser G, Tamin H (2010) Prevalence of smoking during pregnancy and associated risk factors among Canadian women: a national survey. BMC Pregnancy Childbirth 10(24):24-25. https://doi.org/10.1186/1471-2393-1024

Andersson L, Sundstrom-Poromaa I, Wulff M, Astrom M, Bixo M (2006) Depression and anxiety during pregnancy and six months 
postpartum: a follow-up study. Acta Obstet Gynecol Scand 85(8):937-944. https://doi.org/10.1080/00016340600697652

Balwicki L, Zarzecna-Baran M, Wierucki L, Jedrzejczyk T, Strahl M, Wrotkowska M, Goniewicz ML, Zdrojewski T (2016) Smoking among pregnant women in small towns in Poland. Int J Public Health 61(1):111-118. https://doi.org/10.1007/s00038-0150735-2

Beijers C, Ormel J, Meijer J, Verbeek T, Bockting C, Burger H (2014) Stressful events and continued smoking and continued alcohol consumption during midpregnancy. PLoS ONE 9(1):e86359. https://doi.org/10.1371/journal.pone.0086359

Blaga OM, Brinzaniuc A, Rus IA, Chereches RM, Wallis AB (2017) Smoking and smoking cessation during pregnancy: an analysis of a hospital based cohort of women in Romania. J Community Health 42(2):333-343. https://doi.org/10.1007/s10900-0160259-6

Coleman-Cowger V, Koszowski B, Rosenberry ZR, Terplan M (2013) Factors associated with early pregnancy smoking status among low-income smokers. Matern Child Health J 20(5):1054-1060. https://doi.org/10.1007/s10995-0151891-y

Cox JL, Holden JM, Sagovsky R (1987) Detection of postnatal depression: development of the 10-item Edinburgh Postnatal Depression Scale. Br J Psychiatry 150:782-787. https://doi.org/ 10.1192/bjp.150.6.782

Doz J, Gasulla G, Cárceles S, Guerrero I, Tintó A, Prat C, Rosell M (2004) Evolución del hábito tabáquico durante el embarazo y el posparto. Aten Primaria 34(9):465-471. https://doi.org/10.1016/ S0212-6567(04)79532-3

Driezen P, Abdullah AS, Nargis N, Hussain AKMG, Fong GT, Thompson ME, Quah ACK, Xu S (2016) Awareness of tobaccorelated health harms among vulnerable populations in Bangladesh: findings from the International Tobacco Control (ITC) Bangladesh Survey. Int $J$ Environ Res Public Health 13(9):848-862. https://doi.org/10.3390/ijerph13090848

Dupraz J, Graff V, Barasche J, Etter JF, Boulvain M (2013) Tobacco and alcohol during pregnancy: prevalence and determinants in Geneva in 2008. Swiss Med Wkly 143:w13795. https://doi.org/ 10.4414/smw.2013.13795

Erlingsdottir A, Sigurdsson E, Steinar J, Kristjansdottir H, Sigurdsson J (2014) Smoking during pregnancy: childbirth and health study in primary care in Iceland. Scand J Prim Health Care 32(1):11-16. https://doi.org/10.3109/02813432.2013.869409

Field T (2011) Prenatal depression effects on early development: a review. Infant Behav Dev 34(1):1-14. https://doi.org/10.1016/j. infbeh.2010.09.008

Figueiredo B, Conde A (2011) Anxiety and depression in women and men from early pregnancy to 3-months postpartum. Arch Womens Ment Health 14(3):247-255. https://doi.org/10.1007/ s00737-011-0217-3

Figueiredo B, Canario C, Field T (2014) Breastfeeding is negatively by prenatal depression and reduces postpartum depression. Psychol Med 44(5):927-936. https://doi.org/10.1017/ S0033291713001530

Flensborg-Madsen T, Bay von Scholten M, Meulengracht Flachs E, Lykke Mortensen E, Prescott E, Schurmann Tolstrup J (2011) Tobacco smoking as a risk factor for depression: a 26-year population-based follow-up study. J Psychiatr Res 45(2):143-149. https://doi.org/10.1016/j.jpsychires.2010.06.006

Giglia RC, Binns CW, Alfonso HS, Zhan Y (2007) Which mothers smoke before, during and after pregnancy? Public Health 121(12):942-949. https://doi.org/10.1016/j.puhe.2007.04.007

Goedhart G, van der Wal M, Cuijpers P, Bonsel G (2009) Psychosocial problems and continued smoking during pregnancy. Addict Behav 34(4):403-406. https://doi.org/10.1016/j. addbeh.2008.11.006
Haslam C, Lawrence W, Haefeli K (2003) Intention to breastfeed and other important health-related behaviour and beliefs during pregnancy. Fam Pract 20(5):528-530. https://doi.org/10.1093/ fampra/cmg506

Irwin L, Johnson J, Bottorff J (2005) Mothers who smoke: confessions and justifications. Health Care Women Int 26(7):577-590. https://doi.org/10.1080/07399330591004890

Joseph HM, Emery RL, Bogen DL, Levine MD (2017) The influence of smoking on breast feeding among women who quit smoking during pregnancy. Nicotine Tob Res 19(5):652-655. https://doi. org/10.1093/ntr/ntw254

Krstev S, Marinkovic J, Simic S, Kocev N, Bondy S (2012) Prevalence and predictors of smoking and quitting during pregnancy in Serbia: results of a national representative survey. Int J Public Health 57(6):875-883. https://doi.org/10.1007/ s00038-011-0301-5

Linares-Scott T, Heil S, Higgins S, Badger G, Bernstein I (2009) Depressive symptoms predict smoking status among pregnant women. Addict Behav 34:705-708. https://doi.org/10.1016/j. addbeh.2009.04.003

Massey SH, Comptom MT (2013) Psychological differences between smokers who spontaneously quit during pregnancy and those who do not: a review of observational studies and directions for future research. Nicotine Tob Res 15(2):307-319. https://doi.org/ $10.1093 / \mathrm{ntr} / \mathrm{nts} 142$

Maxson P, Edwars S, Ingram A, Miranda ML (2012) Psychosocial differences between smokers and non-smokers during pregnancy. Addict Behav 37(2):153-159. https://doi.org/10.1016/j. addbeh.2011.08.011

Meghea CI, Rus D, Rus IA, Holtrop JS, Roman LA (2010) Smoking during pregnancy and associated risk factors in a sample of Romanian women. Eur J Public Health 22(2):229-233. https:// doi.org/10.1093/eurpub/ckq189

Míguez MC, Pereira B (2018) Prevalence of smoking in pregnancy: optimization of the diagnosis. Med Clín 151(3):124-125. https:// doi.org/10.1016/j.medcli.2017.11.001

Minichino A, Bersani FS, Caló WK, Spagnoli F, Francesconi M, Vicinanza R, Delle Chjaie R, Biondi M (2013) Smoking behaviour and mental health disorders: mutual influences and implications for therapy. Int $\mathrm{J}$ Environ Res Public Health 10(10):4790-4811. https://doi.org/10.3390/ijerph10104790

Mook-Kanamori DO, Steegers EA, Eilers PH, Raat H, Hofman A, Jaddoe VW (2010) Risk factors and outcomes associated with first-trimester fetal growth restriction. JAMA 303(6):527-534. https://doi.org/10.1001/jama.2010.78

Orr ST, Blazer DG, Orr CA (2012) Maternal prenatal depressive symptoms, nicotine addiction, and smoking-related knowledge, attitudes, beliefs, and behaviors. Matern Child Health J 16(5):973-978. https://doi.org/10.1007/s10995011-0822-9

Orton S, Bowker K, Cooper S, Naughton F, Ussher M, Pickett K, Leonardi-Bee J, Sutton S, Dhalwani NN, Coleman T (2014) Longitudinal cohort survey of women's smoking behaviour and attitudes in pregnancy: study methods and baseline data. BMJ Open 4:e004915. https://doi.org/10.1136/bmjopen-2014-004915

Schneider S, Huy C, Schutz J, Diehl K (2010) Smoking cessation during pregnancy: a systematic literature review. Drug Alcohol Rev 29(1):81-90. https://doi.org/10.1111/j.1465-3362.2009. 00098.x

Smedberg J, Lupattelli A, Mardby AC, Nordeng H (2014) Characteristics of women who continue smoking during pregnancy: a cross-sectional study of pregnant women and new mothers in 15 European countries. BMC Pregnancy Childbirth 14:213-228. https://doi.org/10.1186/1471-2393-14-213

Spielberger CD, Gorsuch RL, Lushene R (1970) Manual for the statetrait anxiety inventory (STAI). Consulting Psychologist Press, Palo Alto (Spanish version, Ediciones TEA, Madrid, 1982) 
Suzuki K, Sato M, Tanaka T, Kondo N, Yamagata Z (2010) Recent trends in the prevalence of and factors associated with maternal smoking during pregnancy in Japan. J Obstet Gynaecol Res 36(4):745-750. https://doi.org/10.1111/j.1447-0756.2010.01206.

Taylor G, McNeill A, Girling A, Farley A, Lindson-Hawley N, Aveyard P (2014) Change in mental health after smoking cessation: systematic review and meta-analysis. BMJ 348:g1151. https://doi.org/10.1136/bmj.g1151

Tong VT, Farr SL, Bombard J, D'Angelo D, Ko JY, England LJ (2016) Smoking before and during pregnancy among women reporting depression or anxiety. Obstet Gynecol 128(3):562-570. https://doi.org/10.1097/AOG.000000000000 1595

U.S. Department of Health and Human Services (2014) The health consequences of smoking-50 years of progress: a report of the surgeon general. Public Health Service, Rockville
Vázquez MB, Míguez MC (2019) Validation of the Edinburgh Postnatal Depression Scale as a screening tool for depression in Spanish pregnant women. J Affect Disord 246:515-521. https:// doi.org/10.1016/j.jad.2018.12.075

Ystrom E (2012) Breastfeeding cessation and symptoms of anxiety and depression: a longitudinal cohort study. BMC Pregnancy Childbirth 12(1):36-41. https://doi.org/10.1186/1471-2393-1236

Zhu SH, Valvo A (2002) Depression and smoking during pregnancy. Addict Behav 27(4):649-658. https://doi.org/10.1016/S03064603(01)00199-X

Publisher's Note Springer Nature remains neutral with regard to jurisdictional claims in published maps and institutional affiliations. 